and rate of rise of melanoma mortality are known. One group is then subjected to educational material to which the control group is not exposed and changing patterns of presentation and mortality compared in the two groups. Although this is what was originally planned in Scotland, it was quickly apparent that television was by far the most powerful educational medium, and television channels are relatively unrestricted in their distribution. Furthermore, a story regarded as newsworthy in one area is quickly publicised by television, radio, and newspapers in adjacent areas. In addition, organisers of campaigns such as this have no control over the spread of information in the secondary wave of publicity in women's magazines, etc. Thus, although not ideal, it was necessary to accept the compromise of changes in thickness and mortality in the intervention group before and after intervention as a reasonable measure of efficacy.

\section{Conclusion}

In conclusion, audit of the west of Scotland melanoma education campaign shows encouraging evidence that for women the appropriate population has been targeted and patients are now attending for treatment with thinner primary melanomas. The number of thick melanomas diagnosed in women and the melanoma related mortality in women both showed a downward trend. Alternative approaches seem to be needed to achieve a similar result in men.

We thank the Camilla Samuels Fund, which funded part of the educational campaign; the Cancer Research Campaign, which funds the Scottish Melanoma Group; and Dr A Osterlind for access to data from the Danish cancer registry.

1 MacKie RM, Aitchison TC, Hunter JAA, Hole D, McLaren K, Rankine R, et al. Malignant melanoma in Scotland 1979-89. Lancet (in press).

2 Doherty VR, MacKie RM. Reasons for poor prognosis in British patients with cutaneous malignant melanoma. $B M \mathcal{F}$ 1986;292:987-9.

3 Doherty VR, MacKie RM. Experience of a public education programme on early detection of cutaneous malignant melanoma. $B M \mathcal{J} 1988 ; 297: 388-91$. Cox DR. The analysis of binary data. London: Methuen, 1970.

5 Smith AJ. The Queensland melanoma project. An exercise in health education. BMF 1979;i:253-4.

6 McLeod GR. Control of melanoma in high-risk populations. In: Elwood JM ed. Melanoma and naevi. Vol 9. Pigment cell. Basel: Karger, 1988:131-9.

7 Field SI. Melanoma/skin cancer screening in Michigan. F Am Acad Dermatol 1987;16:578-83.

(Accepted 19 February 1992)
(Medical Hospital and Research Centre and Collaborating Centre for Research, Moradabad, India)

Ram B Singh, director, cardiovascular research Shanti S Rastogi, consultant Rakesh Verma, consultant B Laxmi, dietitian Reema Singh, dietitian S Ghosh, dietitian Mohammad A Niaz, research associate

Correspondence to: Dr Ram B Singh, Medical Hospital and Research Centre, Civil Lines, Moradabad-10, UP India.

BMF 1992;304:1015-9

\title{
$2 x$ \\ Randomised controlled trial of cardioprotective diet in patients with recent acute myocardial infarction: results of one year follow up $/ /$
}

\author{
Ram B Bingh, Shanti S Rastogi, Rakesh Verma, B/Laxmi, ReemaSingh, S_Ghosh, \\ Mohammad AyNiaz
}

\begin{abstract}
Objective - To test whether a fat reduced diet rich in soluble dietary fibre, antioxidant vitamins, and minerals reduces complications and mortality after acute myocardial infarction.
\end{abstract}

Design-Randomised, single blind, controlled trial.

Setting-Primary and secondary care research centre for patients with myocardial infarction.

Subjects-505 patients with suspected acute myocardial infarction. Those with definite or possible acute myocardial infarction and unstable angina based on World Health Organisation criteria were assigned to diet $A(n=204)$ or diet $B(n=202)$ within 24-48 hours of infarction.

Interventions - Both groups were advised to follow a fat reduced diet. Group A was also advised to eat more fruit, vegetables, nuts, and grain products.

Main outcome measures-Mortality from cardiac disease and other causes. Serum lipid concentrations and compliance with diet.

Results-Blood lipoprotein concentrations and body weight fell significantly in patients in group $A$ compared with those in group $B$ (cholesterol fell by $0.74 \mathrm{mmol} / \mathrm{l}$ in group $A v 0.32 \mathrm{mmol} / \mathrm{l}$ in group $B, 95 \%$ confidence interval of difference 0.14 to 0.70 , and weight by $7.1 v 3.0 \mathrm{~kg}, 0.52$ to 7.68 ). The incidence of cardiac events was significantly lower in group $\mathbf{A}$ than group B (50 $v 82$ patients, $p<0.001)$. Group A also had lower total mortality ( $21 v 38$ died, $p<0.01$ ) than group $B$.

Conclusions-Comprehensive dietary changes in conjunction with weight loss immediately after acute myocardial infarction may modulate blood lipoproteins and significantly reduce complications and mortality after one year.

\section{Introduction}

Epidemiological studies show that diet has a definite correlation with coronary heart disease ${ }^{1}$ and that the risks associated with a high fat diet remain even after the occurrence of disease and acute myocardial infarction. ${ }^{2}$ There is evidence that hypercholesterolaemia can inhibit the secretion of endothelial dependent relaxant factor ${ }^{3}$ and predisposes to thrombosis and atherosclerosis. ${ }^{4}$ Reduction in blood lipid concentration has been shown to be associated with a significant decrease in the rate of non-fatal infarctions..$^{5-8}$ Recently, patients having an increased intake of fish after acute myocardial infarction were shown to have a $29 \%$ decrease in all cause mortality compared with the control group after two years' follow up. ${ }^{9}$ There is consistent evidence that common Indian foods, such as onion; garlic; guava; star gooseberry; fenugreek seeds; mushrooms; black, red, and Bengal grams; trichosanthes; bitter gourd; soya beans; ground nut, soya bean, and sunflower oils; and almonds and walnuts can modulate blood concentrations of lipids and glucose and fibrinolytic activity leading to reductions in atherosclerosis. ${ }^{10-18}$ The clinical effects of diet rich in these foods may be the same as that of taking $180 \mathrm{mg}$ aspirin daily. ${ }^{19} \mathrm{We}$ have previously shown that a diet rich in fibre, antioxidant vitamins, and minerals given to patients with acute myocardial infarction significantly reduced cardiovascular events over six weeks. ${ }^{20}$ We report the results of a one year follow up of patients in this experiment.

\section{Patients and methods}

Details of methods, baseline findings, and design of the study have been described. ${ }^{20}$ In brief, all patients admitted to our centre with a clinical diagnosis of suspected myocardial infarction $(n=505)$ within the past 24 hours were considered for the study. Diagnosis of acute myocardial infarction was based on World Health Organisation criteria. ${ }^{21}$ Patients were included if they had acute myocardial infarction, possible acute myocardial infarction, or unstable angina pectoris. Exclusion criteria were disliking the intervention 
diet (12 patients); presence of cancer, diarrhoea, or dysentery and blood urea concentration more than $400 \mathrm{mg} / \mathrm{l}$ (25); death before randomisation (20); and non-cardiac chest pain (42). Patients were kept under surveillance for 24 hours after the clinical diagnosis of acute myocardial infarction, during which time dietary intake, drug treatment, and complications were recorded. Clinical, electrocardiographic, radiological, and biochemical data were also obtained on the patients during the first 24 hours of surveillance. Details of blood pressure measurement and criteria for presence of risk factors have been described..$^{20}$ All participating patients gave written informed consent.

\section{STUDY DESIGN}

Patients with suspected clinical diagnosis of acute myocardial infarction were individually randomised by the dietitian and pharmacists and assigned a diet by blindly selecting a precoded sequence of cards designated diet $\mathrm{A}$ or diet $\mathrm{B}$ from a stack with an equal number in each. The doctor was blind to the assigned diet. All the patients remained in the hospital for 10-30 days. In both diets meat, eggs, hydrogenated oils, butter, and clarified butter were replaced with vegetarian meat substitutes and soya bean, sunflower, and ground nut oils so as to provide a prudent diet reflecting the recommendations of the American Heart Association. Group A patients were also advised to eat fruit, vegetables, pulses, nuts, and fish. ${ }^{20}$ The goal was to provide at least $400 \mathrm{~g} /$ day of fruits and vegetables. These foods are known for their high contents of soluble dietary fibre; free radical inhibitors vitamins A, $\mathrm{C}, \mathrm{E}$, and carotene; and minerals selenium copper, etc. ${ }^{1122}$ In both groups, patients had a mainly vegetarian diet, eating eggs $4-5$ times a week and meat $1-2$ times a week. Other health related advice, such as stopping smoking, reducing alcohol intake, counselling to relieve mental stress and on physical activity, was given to both groups. However, though patients in group $\mathrm{A}$ had the advice regularly reinforced, those in group B were left to usual care after the initial advice. The dietitian giving the advice was not blinded. Dietary intake before admission to hospital was estimated in both groups by taking a detailed history of prestudy food intake from spouses.

All the patients completed records of symptoms of angina pectoris, including daily doses of trinitrate and other drugs, and also dietary diaries with the help of the dietitian on days 3,6 , and 10 after infarction and then every week for six weeks and finally every one to 12 weeks. Dietary compliance was checked and reinforced daily during admission to hospital (10-30 days) by a dietitian and later one to 12 weekly, depending on the seriousness of the infarction and frequency of clinic visits, by showing food models and food portions and asking probing questions on diet. Each patient was counselled regularly at separate counselling sessions and asked to complete a questionnaire about dietary intake, smoking, alcohol intake, and drug intake to enforce drug and dietary compliance and to stop or reduce smoking and alcohol intake in both groups. Drug compliance was checked by counting tablets. Nutrient intakes were calculated from Indian food composition tables ${ }^{22}$ based on the results questionnaires (and weight of fruits and vegetable) completed at one year. Body weights after removing clothes and shoes were recorded by the pharmacist to the nearest $0 \cdot 1 \mathrm{~kg}$.

\section{DATA COLLECTION}

Clinical data, complications, drug treatment, morbidity, and mortality were regularly recorded for one year by the doctor blinded to dietary regimens. Blood pressure, heart rate, and a 12 lead electrocardiogram were recorded at frequent intervals and whenever indicated at a visit to clinic. Angina pectoris and arrhythmias were diagnosed based on criteria described earlier. ${ }^{20}$ Heart failure, left ventricular strain, heart enlargement, and diagnosis of cardiovascular events was based on criteria described earlier. ${ }^{2021}$

Information from the questionnaires was quantified by a formula. A total score of 1 indicated $100 \%$ adherence to the recommended changes in the diet, smoking, alcohol intake, and weight and $\mathrm{O}$ indicated no adherence. Patients who consumed more than our minimum recommendation of $400 \mathrm{~g} /$ day of fruit and vegetables scored greater than 1 . The scores were multiplied by 100 to convert into percentages.

Biochemical data were obtained at entry to study, after six weeks, and then after one year in all the participants. A venous blood sample was drawn in a fasting state and analysed for blood counts and haemoglobin, urea, glucose, cardiac enzyme, tota cholesterol, ${ }^{23}$ high and low density lipoprotein cholesterol, triglyceride, ${ }^{24}$ and electrolyte concentrations. High density lipoprotein cholesterol was measured after precipitation of very low density lipoprotein and low density lipoprotein by an enzymatic method..$^{23}$ In all patients with higher blood lipid concentrations measurements were repeated to confirm the results. Cardiac enzymes were assayed as reported earlier. ${ }^{20}$

Data were analysed on the basis of intention to treat, and in all outcome analyses during follow up last available clinical or laboratory data were incorporated for patients lost to follow up or who had died. Those patients admitted with chest pain who showed no signs of definite or possible acute myocardial infarction but who had unstable angina pectoris were also included in the analysis. Only p values $<0.05$ by the two tailed test were considered significant. We used Student's $t$ test and the two sample $t$ test to compare changes in the two groups and the $\mathrm{Z}$ score test to compare proportions.

\section{Results}

Over three years 505 patients with suspected acute myocardial infarction were considered for entry to the study, and 406 of them were randomly assigned to diet A or diet B. Details of baseline findings have been described. ${ }^{20}$ Of the 406 patients who entered the trial, 204 (mean age 50.5 (SD 9.3) years, body mass index $24 \cdot 3(1 \cdot \mathrm{l}) \mathrm{kg} / \mathrm{m}^{2}$ ) received diet A (cardiovasoprotective) and 202 (mean age $52.0(8 \cdot 3)$ years, body mass index $\left.23.3(0.8) \mathrm{kg} / \mathrm{m}^{2}\right)$ diet $\mathrm{B}$. At entry to the study risk factors such as male sex $(180(88 \%)$ group A $v 185$ $(92 \%)$ group B), mean blood pressures $(132 \cdot 5 / 85 \cdot 3 v$ $134 \cdot 2 / 88 \cdot 4 \mathrm{~mm} \mathrm{Hg}$ ), and lipoprotein concentrations, were comparable in the two groups. There were slightly more smokers $(74(36 \%) v 70(35 \%))$ and a slightly lower alcohol intake $(45(22 \cdot 0 \%) v 50(24 \cdot 7 \%) \mathrm{g} /$ day) in group A than in group B. Sites of acute myocardial infarction as determined by electrocardiography, and initial cardiac enzymes concentrations were similar in both groups. Drug treatment, which included daily doses of propranolol $40-240 \mathrm{mg}(95(46 \%)$ $v 88(44 \%)$ patients), verapamil $20-60 \mathrm{mg}(50(25 \%) v 55$ $(27 \%)$ ), nitrates $60-180 \mathrm{mg}(200(98 \%) v 1.96(97 \%))$, frusemide $20-80 \mathrm{mg}(29(14 \%) \quad v 36(18 \%))$, and aspirin $175-355 \mathrm{mg}(185(91 \%) v 197(98 \%))$, was not significantly different in the two groups. All the patients entered the trial within 24 to 48 hours of an acute myocardial infarction. The numbers of patients with a diagnosis of possible acute myocardial infarction (28 $(14 \%) v 36(18 \%))$ and unstable angina $(10(5 \%) v 9$ (4\%)) were also comparable between the two groups: Most patients had left hospital by the 11th day in both group A (165 (81\%)) and group B (168 (83\%)).

Although the nutrient intakes before entry were similar in the two groups, after one year patients in group A received a significantly higher precentage of energy from vegetable proteins; complex carbohy- 
drates; polyunsaturated fatty acids; fibre in the form of fruits, vegetables, nuts; fish; and soya bean, sunflower, and ground nut oils. They also received less total energy during the first six weeks after acute myocardial infarction and decreased cholesterol and saturated fatty acids during one year follow up than did group B. Adherence to the diet and health recommendations was significantly higher in group A than group B (table I). In group $B$ the nutrient intakes before entry to the study were similar to those at one year follow up. However, after eight weeks they received a higher polyunsaturated to saturated fat ratio and lower cholesterol intake than before entry (tables I, II).

Though both group A and group B received a fat modified diet, at eight weeks group A also consumed significantly more fruits and vegetables. After 24 and 36 weeks group B had increased their intake of cholesterol and saturated fat while group A maintained excellent compliance with the diet (tables I and II). Of 406 patients initially randomised, six in group A and five in group $B$ were lost to follow up. Of the remaining patients, 52 in group A and 58 in group B missed their follow up visits after discharge from the hospital but were later recovered to the study during clinic visits. Patients in group A who had missed follow up appointments showed substantial decreases in blood lipid concentration and weight, suggesting that they had been following the dietary advice. Side effects of the cardiovasoprotective A diet were mild belching and fullness in a few patients.
Blood lipids and glucose concentrations-Although lipid concentrations before the trial were similar in both groups, at one year there was a significant decrease in blood lipids. In both groups most patients $(80 \cdot 2 \%)$ had serum cholesterol concentrations of 4.64$7 \cdot 02 \mathrm{mmol} / \mathrm{l}$ (table III).

Body weight - Initial body weights were $(66.6$ (SD $10 \cdot 5)$, range $52-84 \mathrm{~kg})$ in group $A$ and $(65 \cdot 3(8 \cdot 8)$, 52 $83 \mathrm{~kg}$ ) in group B at entry to the study. After one year weight had fallen by $6.3 \mathrm{~kg}$ in group A (to $59(7 \cdot 7)$, 51 $73 \mathrm{~kg}$ ) and by $2.4 \mathrm{~kg}$ in group B (to $64 \cdot 2(10 \cdot 3), 52-$ $76 \mathrm{~kg}$ ). In group A 117 patients lost more than $0.5 \mathrm{~kg}$ compared with 32 patients in group B. Within group A a separate analysis of data on the 117 patients who lost more than $0.5 \mathrm{~kg}$ showed a more significant change in blood lipoprotein concentrations compared with changes in the other patients (table IV).

Smoking-Smoking was completely stopped in both the groups during admission to hospital. However, after discharge from the hospital 24 out of 72 smokers in group A and 18 out of 70 in group B started smoking again (4-10 cigarettes/day) during the one year follow up.

Complications and cardiac events-The rate of complications was significantly lower in group A than group B and was lowest among those in group A who had lost more than $0.5 \mathrm{~kg}$ after one year of follow up (table V). Cardiac events (non-fatal acute myocardial infarction, fatal acute myocardial infarction, and sudden cardiac deaths) occurred significantly less often

TABLE I - Energy and nutrient intakes before entry and one year after entry in patients receiving cardiovasoprotective diet $A$ and diet $B$. Values are means (SDs)

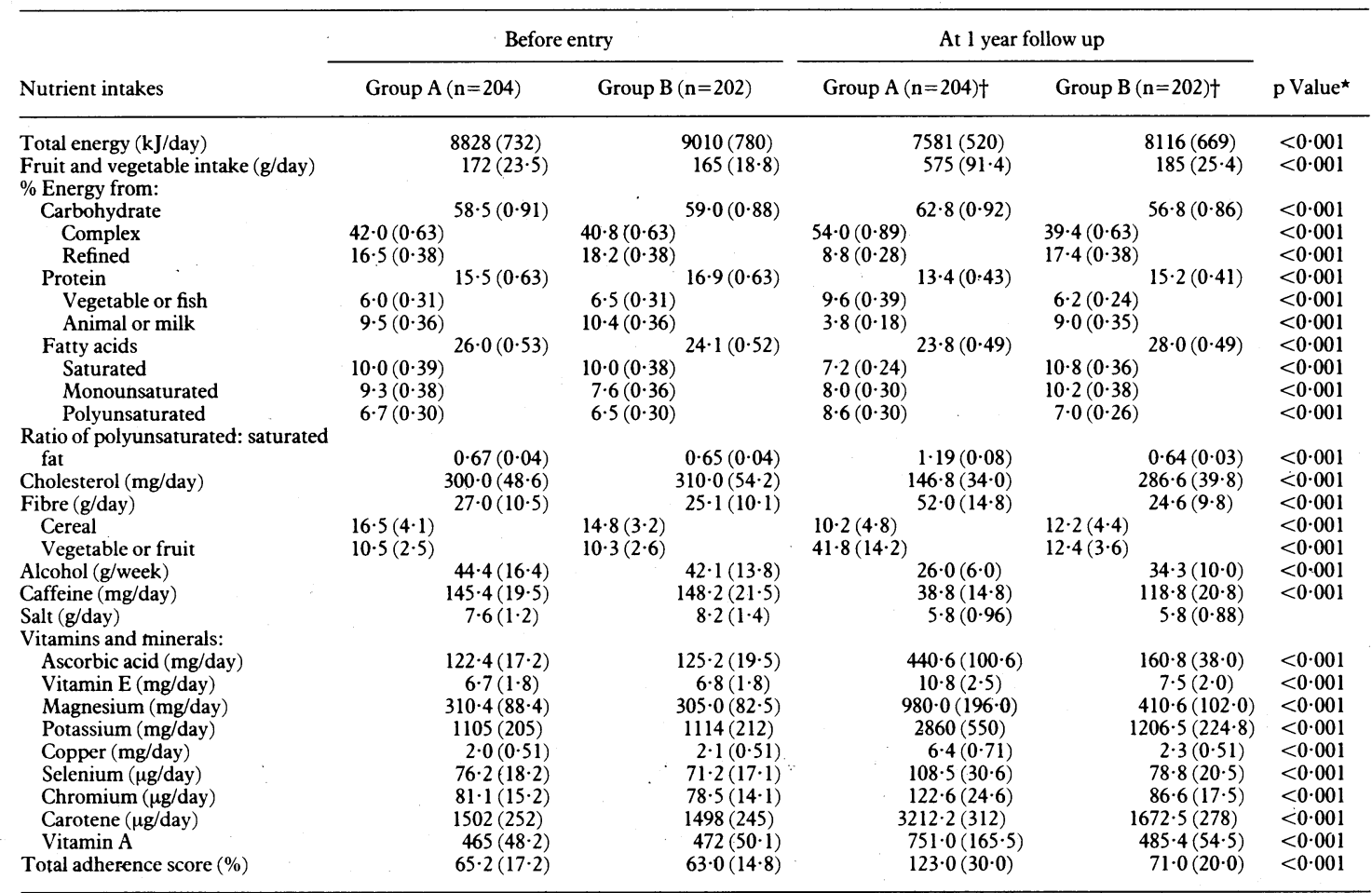

*Statistical significance by Student's $t$ test for comparison of group A and B after one year.

tAt one year dietary intakes data were available for 177 patients in group $A$ and 159 in group $B$.

TABLE II -Effect of dietary advice on daily nutrient intakes at different periods of follow up. Values are means (SDs)

\begin{tabular}{|c|c|c|c|c|c|c|}
\hline \multirow[b]{2}{*}{ Nutrient intakes } & \multicolumn{2}{|c|}{8 weeks } & \multicolumn{2}{|c|}{24 weeks } & \multicolumn{2}{|c|}{36 weeks } \\
\hline & Group A & Group B & Group A & Group B & Group A & ${ }^{\circ}$ Group B \\
\hline$\%$ Energy from fat & $23.9(0.59)$ & $28.0(0.59)$ & $24.5(0.61)$ & $28 \cdot 4(0 \cdot 62)$ & $24 \cdot 2(0 \cdot 60)$ & $29 \cdot 0(0 \cdot 62)$ \\
\hline Polyunsaturated: saturated ratio & $1 \cdot 17(0.03)$ & $0.89(0.03)$ & $1 \cdot 14(0.03)$ & $0.83(0.03)$ & $1.16(0.03)^{\star \star}$ & $0.71(0.03)$ \\
\hline Cholesterol (mg/day) & $186 \cdot 8(48 \cdot 6)$ & $216 \cdot 6(59 \cdot 6)$ & $160 \cdot 5(36 \cdot 2)^{\star \star}$ & $242 \cdot 3(68 \cdot 4)$ & $166(43 \cdot 4)^{\star \star}$ & $275 \cdot 4(55 \cdot 4)$ \\
\hline Total fibre (g/day) & $50 \cdot 6(15 \cdot 6)^{\star}$ & $24 \cdot 6(9 \cdot 8)$ & $50 \cdot 8(16 \cdot 2)^{\star}$ & $26 \cdot 2(10 \cdot 1)$ & $48 \cdot 2(14 \cdot 2)$ & $23 \cdot 2(8 \cdot 2)$ \\
\hline Fruit and vegetable (g/day) & $582(98 \cdot 8)^{\star}$ & $180(28 \cdot 6)$ & $590(95.4)^{\star}$ & $190(30 \cdot 1)$ & $575(88.5)^{\star}$ & $186(25 \cdot 6)$ \\
\hline Adherence score $(\%)$ & $124(30 \cdot 6)$ & $70(20 \cdot 7)$ & $124(30 \cdot 5)$ & $67(20.5)$ & $121(30 \cdot 5)$ & $72(20 \cdot 7)$ \\
\hline
\end{tabular}

${ }^{\star} \mathrm{p}<0.001,{ }^{\star \star} \mathrm{p}<0.01$ for comparison between groups A and B by Student's $t$ test. 


\begin{tabular}{|c|c|c|c|c|c|}
\hline & \multicolumn{2}{|c|}{ Group A } & \multicolumn{2}{|c|}{ Group B } & \multirow{2}{*}{$\begin{array}{c}\text { Difference between } \\
\text { groups ( } 95 \% \text { confidence } \\
\text { interval) }\end{array}$} \\
\hline & $\begin{array}{l}\text { Baseline } \\
(n=204)\end{array}$ & $\begin{array}{c}\text { Changes at } 1 \text { year } \\
(n=204) \dagger\end{array}$ & $\begin{array}{l}\text { Baseline } \\
(n=202)\end{array}$ & $\begin{array}{c}\text { Changes at } 1 \text { year } \\
(n=202) \dagger\end{array}$ & \\
\hline Total cholesterol $(\mathrm{mmol} / \mathrm{l})$ & $5 \cdot 83(1 \cdot 19)$ & $-0 \cdot 74$ & $5 \cdot 91(1 \cdot 11)$ & $-0 \cdot 32$ & $0.42(0.14 \text { to } 0.70)^{\star}$ \\
\hline Low density lipoprotein cholesterol $(\mathrm{mmol} / \mathrm{l})$ & $4.39(0.73)$ & $-0 \cdot 54$ & $4 \cdot 31(0 \cdot 64)$ & $-0 \cdot 24$ & $0.30(0.07 \text { to } 0.53)^{\star}$ \\
\hline High density lipoprotein cholesterol (mmol/l) & $1 \cdot 15(0 \cdot 29)$ & +0.07 & $1 \cdot 10(0 \cdot 25)$ & -0.04 & $0.11(-0.03 \text { to } 2 \cdot 40)^{\star \star}$ \\
\hline Triglyceride $(\mathrm{mmol} / \mathrm{l})$ & $1.94(0.29)$ & -0.29 & $1.97(0 \cdot 26)$ & $-0 \cdot 12$ & $0.17(-0.02 \text { to } 0.35)^{\star}$ \\
\hline Fasting blood glucose $(\mathrm{mmol} / \mathrm{l})$ & $6.94(0.57)$ & -1.36 & $6.80(0.53)$ & -0.65 & $0.71(0.20 \text { to } 1.22)^{\star}$ \\
\hline Blood urea $(\mathrm{mmol} / \mathrm{l})$ & $4.03(0.96)$ & -0.30 & $4 \cdot 33(1.08)$ & -0.53 & $0.23(-0.06$ to 0.52$)$ \\
\hline \multicolumn{6}{|l|}{ Blood pressures $(\mathrm{mm} \mathrm{Hg})$ : } \\
\hline Systolic & $132.5(5.4)$ & $-13 \cdot 4$ & $134 \cdot 2(7 \cdot 5)$ & $-5 \cdot 2$ & $8 \cdot 2(3 \cdot 0 \text { to } 13 \cdot 1)^{\star \star}$ \\
\hline Diastolic & $85 \cdot 3(2 \cdot 6)$ & $-9 \cdot 3$ & $88 \cdot 4(4 \cdot 2)$ & -3.5 & $5 \cdot 8(2 \cdot 46 \text { to } 9 \cdot 14)^{\star \star}$ \\
\hline
\end{tabular}

${ }^{\star} \mathrm{p}<0.01,{ }^{\star \star} \mathrm{p}<0.05$ by two sample $t$ test.

† At one year data were available for 177 patients in group $A$ and 159 in group $B$.

TABLE IV-Changes in risk factors compared with baseline in patients following cardiovasoprotective diet $A$ according to weight loss at one year. Values are means $(S D s)$

\begin{tabular}{|c|c|c|c|c|c|}
\hline & \multicolumn{2}{|c|}{ Loss $\geqslant 0.5 \mathrm{~kg}$} & \multicolumn{2}{|c|}{ Loss $<0.5 \mathrm{~kg}$} & \multirow{2}{*}{$\begin{array}{c}\text { Difference between } \\
\text { groups ( } 95 \% \text { confidence } \\
\text { interval) }\end{array}$} \\
\hline & $\begin{array}{l}\text { Baseline } \\
(n=117)\end{array}$ & $\begin{array}{l}\text { Change at } 1 \text { year } \\
(n=117) \dagger\end{array}$ & $\begin{array}{l}\text { Baseline } \\
(\mathrm{n}=87)\end{array}$ & $\begin{array}{c}\text { Change at } 1 \text { year } \\
\quad(n=87) \dagger\end{array}$ & \\
\hline Total cholesterol $(\mathrm{mmol} / \mathrm{l})$ & $6 \cdot 07(0 \cdot 87)$ & $-1 \cdot 05$ & $5 \cdot 60(0 \cdot 73)$ & -0.47 & $0.58(0.06 \text { to } 10.90)^{\star}$ \\
\hline Low density lipoprotein cholesterol $(\mathrm{mmol} / \mathrm{l})$ & $4.56(0.73)$ & -0.81 & $4 \cdot 12(0 \cdot 57)$ & -0.39 & $0.42(0.04 \text { to } 8.0)^{\star}$ \\
\hline High density lipoprotein cholesterol $(\mathrm{mmol} / \mathrm{l})$ & $1 \cdot 14(0 \cdot 25)$ & $0 \cdot 09$ & $1 \cdot 17(0 \cdot 29)$ & -0.03 & $0.12(-0.02 \text { to } 0.26)^{\star \star}$ \\
\hline Triglyceride $(\mathrm{mmol} / \mathrm{l})$ & $2.03(0.24)$ & $-0 \cdot 35$ & $1.85(0.19)$ & $-0 \cdot 15$ & $0.20(0.04 \text { to } 0.36)^{\star \star \star}$ \\
\hline Fasting blood glucose $(\mathrm{mmol} / \mathrm{l})$ & $7.08(0.68)$ & -1.69 & $6.84(0.56)$ & -0.91 & $0.78(0.37 \text { to } 1.19)^{\star \star}$ \\
\hline \multicolumn{6}{|l|}{ Blood pressures $(\mathrm{mm} \mathrm{Hg})$ : } \\
\hline Systolic & $136 \cdot 4(7 \cdot 5)$ & $-18 \cdot 6$ & $128 \cdot 5(9 \cdot 6)$ & $-8 \cdot 5$ & $10 \cdot 1(2.63 \text { to } 17 \cdot 57)^{\star \star}$ \\
\hline Diastolic & $86 \cdot 8(3 \cdot 1)$ & $-12 \cdot 4$ & $84 \cdot 2(5 \cdot 1)$ & $-5 \cdot 6$ & $6.8(2 \cdot 13 \text { to } 11 \cdot 27)^{\star \star}$ \\
\hline Body weight $(\mathrm{kg})$ & $68 \cdot 5(5 \cdot 4)$ & $-7 \cdot 1$ & $64 \cdot 2(4 \cdot 2)$ & $-3 \cdot 0$ & $4 \cdot 1(0.52 \text { to } 7.68)^{\star}$ \\
\hline Adherence score (\%) & $46 \cdot 0(11 \cdot 2)$ & $95 \cdot 0$ & $48 \cdot 2(11 \cdot 8)$ & $40 \cdot 0$ & $55.0(14$ to 96$)$ \\
\hline
\end{tabular}

${ }^{\star} \mathrm{p}<0 \cdot 01,{ }^{\star} \mathrm{p}<0.05$ by two sample $t$ test

† At one year laboratory data were available for 102 patients who lost $\geqslant 0.5 \mathrm{~kg}$ and 75 who lost $<0.5 \mathrm{~kg}$

TABLE V-Complications and cardiac events in patients following cardiovasoprotective diet $A$ and fat reducing diet $B$ one year after acute myocardial infarction. Values are numbers (percentages)

\begin{tabular}{|c|c|c|c|c|c|}
\hline & \multicolumn{3}{|c|}{ Group A } & \multirow[b]{2}{*}{$\begin{array}{l}\text { Group B } \\
(n=202)\end{array}$} & \multirow[b]{2}{*}{$\begin{array}{l}\text { Relative risk ( } 95 \% \\
\text { confidence interval) }\end{array}$} \\
\hline & $\begin{array}{c}\text { Loss } \geqslant 0 \cdot 5 \mathrm{~kg} \\
(n=117)\end{array}$ & $\begin{array}{l}\text { Loss }<0 \cdot 5 \mathrm{~kg} \\
\quad(n=87)\end{array}$ & $\begin{array}{l}\text { All patients } \\
(n=204)\end{array}$ & & \\
\hline \multicolumn{6}{|l|}{ Complications: } \\
\hline Angina pectoris & $6(5)^{\star \star}$ & $8(9)$ & $14(7) \star \star \star$ & $46(23)$ & $0.30(0.15$ to 0.45$)$ \\
\hline Positive result on exercise test & $22(19)^{\star \star \star}$ & $42(48)$ & $64(31)^{\star \star \star}$ & $128(63)$ & $0.49(0.39$ to 0.59$)$ \\
\hline Left ventricular strain & $7(6)^{\star \star \star}$ & $12(14)$ & $19(9)^{\star \star}$ & $34(16 \cdot 8)$ & $0.55(0.32$ to 0.79$)$ \\
\hline Left ventricular hypertrophy & $3(3)^{\star}$ & $8(9)$ & $11(5)^{\star \star}$ & $24(17)$ & $0.45(0 \cdot 19$ to $0 \cdot 70)$ \\
\hline NYHA class III and IV & $3(3)^{\star}$ & $5(6)$ & $8(4)$ & $14(7)$ & $0.56(0.18$ to 0.95$)$ \\
\hline Ventricular ectopics ( $8 / \mathrm{min})$ & $6(5)^{\star \star \star}$ & $8(9)$ & $14(7)^{\star \star \star}$ & $42(21)$ & $0.33(0.16$ to 0.49$)$ \\
\hline Ventricular ectopics ( 3 in row) & $1(0 \cdot 9)$ & $2(2)$ & $3(1)^{\star \star \star}$ & $18(9)$ & $0.45(-0.02$ to 0.35$)$ \\
\hline Cardiac events & $20(17)^{\star \star \star}$ & $30(34)$ & . $50(25)^{\star \star \star}$ & $82(41)$ & $0.60(0.31$ to 0.75$)$ \\
\hline Non-fatal myocardial infarction & $12(10)^{\star \star \star}$ & $18(21)$ & $30(15)^{\star \star}$ & $48(24)$ & $0.62(-0.42$ to 0.83$)$ \\
\hline Fatal myocardial infarction & $5(4)^{\star}$ & $8(9)$ & $13(6)$ & $19(9)$ & $0.68(0.32$ to 1.03$)$ \\
\hline Sudden cardiac death (within 1 hour) & $3(6)^{\star}$ & $4(5)$ & $7(3)$ & $15(7)$ & $0.46(0.12$ to 0.29$)$ \\
\hline Suspected cardiac death & & & & $1(0 \cdot 5)$ & \\
\hline Death due to cancer & & & & $1(0 \cdot 5)$ & \\
\hline Death due to stroke & & $1(1)$ & $1(0 \cdot 5)$ & $2(1)$ & $0.49(0.47$ to 1.46$)$ \\
\hline Total cardiac mortality & $8(7)^{\star}$ & $12(14)$ & $20 \cdot(10)^{\star \star}$ & $34(17)$ & $0.58(0.34$ to 0.83$)$ \\
\hline Total mortality & $8(7)^{\star \star \star}$ & $13(16)$ & $21(10)^{\star \star}$ & $38(19)$ & $0.55(0.34$ to 0.75$)$ \\
\hline Cardiac events plus other deaths & $20(17)^{\star \star \star}$ & $31(36)$ & $51(25)^{\star \star \star}$ & $86(43)$ & $0.59(0.46$ to 0.74$)$ \\
\hline
\end{tabular}

${ }^{\star} \mathrm{p}<0.05,{ }^{\star \star} \mathrm{p}<0.01,{ }^{\star \star \star} \mathrm{p}<0.001$, obtained by $\mathrm{Z}$ test.

NYHA $=$ New York Heart Association.

in group A than group B $(50 v 82, \mathrm{p}<0.001)$, and total mortality was also lower in group A (21 $v 38$ deaths, $\mathrm{p}<0.01)$. Within intervention group $A$ the proportion of patients with cardiovascular events was significantly less in the subset of 117 patients who lost $\geqslant 0.5 \mathrm{~kg}$ compared with those who lost $<0.5 \mathrm{~kg}(20 v 30$, $\mathrm{p}<0.05)$; total mortality in these two subsets was not significantly different.

\section{Discussion}

Since most deaths after acute myocardial infarction occur during admission to hospital it may be more beneficial to start the diet immediately after suspicion of an attack. Our study showed that a diet with a high fibre, mineral vitamin, and numerial content associated with weight reduction (tables I-III) initiated within 72 hours of an acute myocardial infarction significantly decreased total mortality from cardiac disease $(p<0.01)$ and all causes $(\mathrm{p}<0.01)$ over one year. There was a significant decrease in total cardiac events, including non-fatal acute myocardial infarction $(p<0.01)$ in patients taking a cardiovasoprotective diet compared with patients taking a fat reduced diet $(50 v 82$, $\mathrm{p}<0.001$ ) (table V). Underlying these beneficial effects patients in group A had sigrificant decreases in blood lipoprotein and fasting blood glucose concentrations in association with a higher total adherence score compared with group B (tables III and IV). Patients in group A who lost more than $0.5 \mathrm{~kg}$ and also had higher adherence scores showed greater changes in blood lipid concentration and had fewer cardiac events compared with patients who had lost less than $0.5 \mathrm{~kg}$ in group $A$ $(p<0.05)$ and patients in group $B(p<0.001$; table IV and $V$ ). The strong relation between adherence to the intervention programme, lipid changes, and cardiac events indicates that the relation is causal because those who made the biggest changes showed highest pro- 
tection from coronary events. ${ }^{78}$ Weight reduction seemed to have an independent beneficial effect.

Several randomised trials have been published in which a low fat diet or one with a high polyunsaturated to saturated fat ratio was given to subjects who had had an acute myocardial infarction. ${ }^{6825-27}$ All the published trials contained less than 500 subjects. Despite a beneficial influence on reinfarction, none showed any reduction in deaths. In contrast with our study in these studies intervention was not initiated until six to eight weeks after acute myocardial infarction, and the diets did not aim at increasing intake of water soluble dietary fibre, antioxidant vitamins, and minerals. ${ }^{689}$ There is epidemiological ${ }^{2829}$ and experimental evidence that soluble dietary fibre, vitamins, and minerals may protect against coronary artery disease by decreasing blood lipids concentrations as well as by inhibiting formation of lipid peroxides, which damage myocardial arterial cells. ${ }^{1128}$ Both of these mechanisms are also known to decrease free radical generation, decrease cell acidosis, inhibit sodium and calcium ion influx into the cell, and prevent structural and functional disorders of cell. ${ }^{411}$ Recently diets rich in fruit and vegetables have been advised by the WHO and United States Department of Health and Human Services for prevention of chronic diseases. ${ }^{30} 31$

Restriction of energy intake can reduce atherosclerosis and coronary deaths ${ }^{32}$ and weight reduction may be associated with reduction in coronary artery disease and all of its risk factors. ${ }^{23}$ Weight reduction may also reduce cardiac enlargement, left ventricular strain, postexercise electrocardiographic changes, and arrhythmias, ${ }^{2}$ possibly by reducing myocardial oxygen requirement and having other beneficial effects on cardiac indices. ${ }^{33}$ Thus the decrease in complications in the intervention group may be due to weight loss as well as to lipid changes. A decreased intake of clarified butter, ${ }^{34}$ a decrease in hyperinsulinaemia due to dietary changes, and a reduction in obesity induced coronary disease (as observed in Indian migrant $\mathrm{s}^{35}$ ) are other possible causes for the reduction in cardiac events.

In dietary trials the issue of compliance to advice is a problem because patients in the intervention group may not eat exactly what they are advised. The control group may also follow some intervention programme. Monitoring of dietary compliance through questionnaires is again open to bias because subjects may have simply learnt to answer what the dietitian wants to hear. However, the seriousness of illness in acute myocardial infarction tends to motivate the patients to eat and follow what they are advised and respond truthfully to questions.

In conclusion, we have shown that a diet in which fruits, vegetables, cereals, nuts, and oil substitute for clarified butter, eggs, and meat together with weight reduction can significantly reduce the number of cardiac events and all cause mortality. An additional finding is the significant decrease in non-fatal acute myocardial infarction in the intervention group compared with the control group. A longer follow up would be necessary to confirm these observations.

1 Shakelle RB, Stamler J. Dietary cholesterol and ischaemic heart disease. Lancet 1989;i:1177-9.
2 Wong ND, Cupples A, Ostfeld AM, Levy D, Kannel WB. Risk factors for longterm coronary prognosis after initial myocardial infarction: The Framingham Study. Am F Epidemiol 1989;130:469-80.

3 Andrews RE, Bruckotorfer KR, Dunn RC, Jacobs M. Low density lipoproteins inhibit endothelium dependent relaxation in a rabbit aorta. Nature 1987;327: 237-9.

4 Horrobin DF, Huang YS. The role of linoleic acid and its metabolite in the lowering of plasma cholesterol and the prevention of cardiovascular disease. Int $f$ Cardiol 1987;17:241-55.

5 Lamm G. Risk factor intervention and prognosis after acute myocardial infarction. Cardiovascular Drug Therapy 1988;2:133-7.

6 Leren P. Prevention of coronary heart disease some results from the Oslo secondary and primary intervention studies. $\mathcal{F}$ Am Coll Nutr 1989;8:407-10.

7 Lipid Research Clinics Programme. The lipid research clinic primary prevention results: reduction in incidence of coronary heart disease. $\mathcal{F} A M A$ 1984;251:351-64.

8 Research Committee. Low fat diet in myocardial infarction: a controlled trial. Lancet 1965;ii:501-4.

9 Burr ML, Fehily AM, Gilbert JF, Rogers S, Holiday RM, Sweetnam PM, et $a l$. Effects of changes in fat, fish, and fibre intakes on death and myocardial reinfarction: diet and reinfarction trial (DART). Lancet 1989;ii:757-61.

10 Arntzenius AC, Kromhout D, Bartn JE, Reiber JHC, Bruschke AVG, Buis Van Gent CM, et al. Diet. Lipoproteins and progression of coronary Van Gent CM, et al. Diet. Lipoproteins and progression of coronary
atherosclerosis. The Leiden intervention trial. $N$ Engl f Med 1985;312: 805-8.

11 Singh RB, Mori H, Kummerow FA, Kokatnoor M. Nutrition in coronary hear disease, Moradabad, India: ICN monograph, 1991.

12 Sharma RD. Hypocholesterolemic agents. Proceedings of the 21st annual meeting of Nutrition Society of India, Nov 24-26, 1988. Hyderabad: Nutrition Society of India, 1989:52-6.

13 Kurup PA. Nutritional factors and atherosclerosis. Proceedings of 21 st annual meeting of Nutrition Society of India, Nov 24-26, 1988, Hyderabad: Nutrition Society of India, 1989:27-37.

14 Singh RB, Verma R, Mehta PJ, Laxmi B, Garg V. Nutritional intervention in acute myocardial infarction. 7 Nutr Med 1990;1:179-86.

15 Sainani GS, Desai DB, More KN. Onion, garlic, and atherosclerosis. Lancet 1976;ii:575-8.

16 Menon S, Kendal RV, Dewar HA, Newell DJ. Effect of onion on blood fibrinolytic activity. $B M \mathcal{F} 1968 ; 3: 351-3$.

7 Boulin DJ. Garlic as a platelet inhibitor. Lancet 1981;i:776.

18 Mathur KS, Khan MA, Sharma RD. Hypocholesterolaemic effect of Bengal gram in man. $B M \mathcal{F} 1968 ; \mathrm{i}: 30-1$.

19 Singh RB, Verma R, Mehta PJ, Rastogi SS. The effect of diet and aspirin on patient outcome after myocardial infarction. Nutrition 1991;7:119-23.

20 Singh RB, Rastogi SS, Verma R, Bolaki L, Singh R, Ghosh S. An Indian experiment with nutritional modulation in acute myocardial infarction. $A m$ f Cardiol 1992;69:879-85.

21 World Health Organisation. Myocardial infarction community register Copenhagen: WHO, 1976

22 Narsinga Rao BS, Deostnale YG, Pant KC: Nutrient composition of Indian foods. Hyderabad: National Institute of Nutrition, 1989.

23 Wilson DE, Spiger MJ. A dual precipitation method for quantitative plasma lipoproteins measurement without ultracentrifugation. $f$ Lab Clin Med 1973;82:413-82.

24 Van Handel E, Zilversmit BD. Micromethod in the direct estimation of serum triglycerides. F Lab Clin Med 1957;60:152-9.

25 Rose GA, Thompson WB, William RT. Corn oil in treatment of ischaemic heart disease. BMF 1965; i: 1531-3.

26 Medical Research Council Research Committee. Controlled trial of soya bean oil in myocardial infarction. Lancet 1968;ii:693-700.

27 Woodhill JM, Palmer AJ, Leelarthalpin B, McGilchrist C, Blacket RB. Low fat, low cholesterol diet in secondary prevention coronary heart disease. Adv Exp Med Biol 1978;109:317-30.

28 Riemersma RA. Risk of angina pectoris and plasma concentrations vitamin A $\mathrm{C}, \mathrm{E}$ and carotene. Lancet 1991;357:1-5.

29 Khaw KT, Barret-Conner E. Dietary fibre and reduced coronary heart disease mortality rates in men and women, a 12 year prospective study. $\mathrm{Am} \mathcal{J}$ Epidemiol 1987;126:1093-102.

30 World Health Organization Expert Committee on Diet. Nutrition and prevention of chronic diseases: report of a WHO study group. Geneva: WHO (in press).
(in

31 United States Departments of Agriculture and Health and Human Services. Revised dietary guidelines for Americans. 3rd ed. Washington, DC: US Department of Agriculture, 1991.

32 Schettler G. Cardiovascular diseases during and after World War II: a comparison of Federal Republic of Germany with other European countries. Prev Med 1979;8:581-90.

33 Bagatell CA, Heymafield SB. Effect of meal size on myocardial oxygen requirements: implications for postmyocardial infarction diets. Am $\mathcal{f}$ Clin Nutr 1984;39:421-6.

34 Jacobson MS. Cholesterol oxides in Indian ghee: possible cause of unexplained high risk of atherosclerosis in Indian immigrant populations. Lance 1987;ii:656-8.

35 McKeigue PM, Shah B, Marmot MG. Relation of central obesity and insulin resistance with high diabetes prevalence and cardiovascular risk in South Asians. Lancet 1991;337:382-6.

(Accepted 10 February 1992) 